\title{
The Recovery Process of Postpartum Psychosis from Both the Woman's and Next of Kin's Perspective - An Interview Study in Sweden
}

\author{
I. Engqvist ${ }^{*}, 1,2$ and K. Nilsson ${ }^{3}$ \\ ${ }^{1}$ School of Life Science, University of Skövde, Sweden \\ ${ }^{2}$ Skaraborg Hospitals, Falköping, Sweden \\ ${ }^{3}$ Institute of Health and Caring Sciences, The Sahlgrenska Academy, University of Gothenburg, Sweden
}

\begin{abstract}
Objectives: The most serious type of psychiatric disorder in connection with childbirth is postpartum psychosis. With this disorder occasionally follows emotional rejection of the infant which has serious long term effect on mother and child. The aim of this study was to explore the experiences of the recovery process of postpartum psychosis from the women, from the partners of the women, and their next of kin.

Methods: Interviews were conducted with seven women, who had previously suffered postpartum psychosis, and six of their next of kin. The interviews were transcribed verbatim and analysed using content analysis.

Results: Two categories emerged: the recovery process and the circumstances of the support provided. The women and their next of kin spoke about the turning point in the illness, their own personal as well as their social recovery, the importance of support not only from relatives and friends, but also from professionals, and the use of medication. However, the key to recovery was an internal decision by the women themselves.

Conclusion: Conclusion is that the recovery from this severe mental disorder requires hard work and the key to their recovery was the decision made by the women. This disorder causes a mental darkness to descend, but at the start of the recovery a dim light shines in the dark tunnel. The nursing staff must be made aware that good sleep is important for the psychiatric treatment and that recovery may take a long time. The nurse needs to provide hope and encouragement, as well as help the woman to recognise the strength that exists within her. To reduce the risk of a recurrence of the disorder, the staff needs to offer follow up visits.
\end{abstract}

Keywords: Content analysis, postpartum psychosis, recovery, relatives, women.

\section{INTRODUCTION}

Usually, when studies have been conducted regarding the disorder of postpartum psychosis that women and their partners have experienced, the focus has been on the psychotic phase. However, in this study, we focus on the women and their next of kin's experiences of the recovery process. Our focus is not on the psychotic stage of the disorder, as this phase has been the subject of several previous studies [1-8].

Postpartum psychosis (PPP) is a severe mental disorder which occurs in close proximity to childbirth. Of newlydelivered women somewhat less than 1/1000 deliveries are expected to become afflicted with this disorder [9]. With this disorder occasionally follows emotional rejection of the infant which has serious long term effect on mother and child. To be diagnosed with PPP according to DSMIII, the onset of the disorder should occur within four weeks of delivery [10]. This condition is characterised by several nights of insomnia, depression or mania, confusion, anxiety,

*Address correspondence to this author at the School of Life Sciences, University of Skövde, Box 408, SE-541 28 Skövde, Sweden;

Fax:+46500448099; E-mails: inger.engqvist@his.se, inger.engqvist@gmail.com marked behavioural disturbance, and loss of insight $[8,11]$, as well as delusions, catatonia, auditory hallucinations almost any symptoms found in psychoses [12]. Furthermore, most women need hospitalised care from 2-3 weeks to 2-3 months [13]. PPP is a medical emergency for which fast identification and evaluation [4] are crucial, in order to implement multi-disciplinary obstetrics and psychiatric care [3], as well as the involvement of the family [7] and the provision of adequate social support [14]. Rarely, the condition can pose a grave risk to both mother and infant, due to suicidal and infanticide tendencies, but they do occur $[13,15,16]$. Nonetheless, the prognosis is generally good and most women can return home well within a relatively short period of time, while others find that it can take 12 months or longer to recover [17,18]. The risk of relapse in a subsequent birth is approximately $50 \%$, especially if the woman has a history of mental illness $[17,19,20]$.

It is obvious from the above that the disorder affects the relationship between the mother and her newborn child [21]. The mother's ability to function effectively as a mother with regard to her newborn child is profoundly affected, but also her ability to care for any older children she may have [22]. Another person deeply affected by this illness is the woman's partner, who is attempting to adjust to the 
transition to fatherhood, the presence of his new baby, as well as to the distress of his partner's illness [23-25]. The extended family, such as the maternal/paternal mother and father, might also be affected by the illness, but only one recent study [8] addressing this topic has been found.

The recovery from mental illness is described as a deeply personal, unique process that involves changing attitudes, values, feelings, goals, skills, and roles. It is a way of living a life that is satisfying, hopeful and meaningful, even with the limitations caused by the disorder. Recovery involves the development of a new purpose when one moves beyond the chaos of the mental suffering [26]. Social relationships with friends, family members, and professionals can be critical to the recovery process. In the social interaction, which may contribute to the recovery process, it is important that the woman feels respected, accepted, seen, and heard [27,28]. However, the most important aspect for recovery is the woman's own determination, her certainty that "I will get through this." The second most important is the other people in her life, such as professionals, close family, other relatives, and friends. These can serve as a sounding board, provide security, hope, support, and assistance of all kinds. Of great importance is also a sense of context, to understand the background and development of the illness, as well as a conception of how to overcome the hardship [29].

Accordingly, although there are several studies concerning PPP that focus on the prevalence, signs and symptoms, the treatment, as well as how the disorder affects the women and their next of kin, research embracing a holistic perspective from different angles has not been conducted in relation to this serious disorder. Nor have any studies been found regarding the perspective of the next of kin. Therefore, we recognise that there is a need to explore PPP from different perspectives, namely, the perspective of the women's partners and that of the next of kin, with regard to the experiences of the recovery process at the conclusion of hospital care as well as following discharge.

Consequently, the aim of this study was to explore the recovery process of postpartum psychosis from the perspective of the women, the women's partners and their next of kin, with regard to their experiences of the process at the conclusion of hospital care and after discharge.

\section{METHOD}

In order to study the experiences of the recovery process after discharge, an explorative qualitative method was chosen [30] and semi-structured interviews were used for data collection. These interviews were conducted during face to face meetings where the intention of the interviewer was to ascertain the informants' point of view and experiences related to the phenomenon being explored [31].

\section{Informants}

During an interview at a local radio station, the first author discussed the disorder of PPP presented in a recent $\mathrm{PhD}$ thesis and the difficulties of coming into contact with the women themselves. The researcher was subsequently contacted by a woman who had been afflicted with the illness nineteen years earlier and who volunteered to be interviewed. The offer was accepted and an interview was carried out. This woman had, via a network of members of a Swedish patient association, contact with several other women, who had previous experience of PPP, and their partners and families. Through this snowball sampling [32], four women, two partners, as well as four next of kin agreed to be interviewed. Subsequently, through reading an article about the researcher in a mental health journal, several more women contacted us and two of them were interviewed. A total of 13 respondents were thus surveyed.

\section{Data Collection}

Data was collected from June 2011 to January 2012. Eleven of the respondents were interviewed in their homes and two in a private room at a nearby library. Broad, openended questions were used in these interviews. First, a few background questions were asked concerning their year of first child birth, year of PPP onset, number of birth when PPP onset, age, and civil status. Second, the women were asked about one main question - "Can you tell me about you experience of the recovery time?" Afterwards, a few questions in relation to the experience of being discharged and support given, as well as their signs of and thoughts concerning recovery, were made. The women were also asked to narrate some events during recovery and described how they felt. During the interview, the second main question to the women was: "Can you tell me about your experience of the time after recovery?" This question was followed up with a few questions concerning their positive or negative consequences of the illness later on in their life. The main question to the next of kin was: "Can you tell about how you experienced your next of kin's recovery?" Similar to the women, this question was followed up by a few questions related to signs of recovery, support, and positive or negative consequences of the illness later on in the life. The interviews were recorded and lasted from approximately 45 to 90 minutes. After the conclusion of the interview, it was discussed and reflected upon.

\section{Data Analysis}

The interviews were analysed, using an inductive content analysis [33], and began with reading the entire interview (unit of analysis) several times to obtain a sense of the whole. With the whole context in mind, the text was condensed and meaning units were extracted and labelled with a code. These codes were compared, on the basis of differences and similarities, and sorted into categories (manifest content) and/or sub-categories. The underlying meaning of the categories (latent content) or themes was then identified [33]. In order to support the descriptions, direct quotes from the interviews were used.

\section{ETHICAL APPROVAL}

The recommended ethical considerations for qualitative research have been considered in this study. Hence, the fundamental ethical demands for the individuals, such as informed consent, confidentiality, and correct use of the findings, have been followed. In addition, research approval 
was obtained from the Regional Ethics Review Board in Gothenburg, Sweden [Dnr 493-05].

\section{RESULTS}

The interviewed women had been afflicted with the illness from between seven years to 32 years ago and at the time of the illness their ages ranged between 24-32 years. At the time of the interviews, the ages of the women ranged between 44-62 years. Three of the next of kin contacted us for interviews, but their afflicted loved ones did not want to participate. For the next of kin, the time since illness had struck their loved ones ranged from six months to 19 years ago. The next of kin were two husbands, one paternal mother, two maternal mothers, and one maternal father. The age for the husbands ranged between 29-32 years at the time of the illness onset, and at the time of the interviews 39-48 years. The age for the other next of kin ranged between 5265 at the time of the illness, and at the time of the interviews 59-72.

All the women recovered from the illness, but it lasted different lengths of time. None of them recovered in just a few weeks; primarily, the length of their hospital stay ranged between 0-21 (mean of 9) days. One of the women managed without hospitalisation, despite strong psychotic symptoms, while three were re-admitted within two months for a second hospital stay lasting 1-3 months. Six of the women have since had periods of hospitalisation with psychosis or depression. None of the women have subsequently given birth.

The results describe how the women and their next of kin experienced the treatment and the recovery from the postpartum psychosis disorder. In order to provide a deeper understanding of the result, it is divided into two main themes and their sub-themes, as described in Table $\mathbf{1 .}$

Table 1. Overview of the Results

\begin{tabular}{|c|c|}
\hline Main Themes & Sub-Themes \\
\hline \hline \multirow{2}{*}{ The recovery } & The turning point \\
& Own recovery \\
& Social recovery \\
\hline Supporting circumstances & Relatives' and friends' support \\
& Professional support \\
& Support through medication \\
\hline
\end{tabular}

\section{The Recovery}

When the women had been sick for some time, they began to think that a recovery was necessary. This was a phase that came at different stages for the women. One of the women described it as a decision that is taken within you. The choices are either to remain in the mental illness, commit suicide and disappear, or to decide to "return to life".

\section{The Turning Point}

As time passed, a decision to return to her child, husband, and the rest of the family gradually emerged. From being trapped in the "psychotic quilt", with very little concern for the family and most importantly showing very little concern and interest in the newborn, consideration that focused on the family grew stronger. A desire to return to "the usual" gradually increased. One woman described how the beginning of the recovery came after her clear decision to return to life and health again.

But then it is this with recovery ... and it is that somewhere you make a decision within yourself ... because it is either choosing death or staying in this ward all your life and giving up. But then I realised that this is not where I should be! This is not where I should be functioning! I have a home, and I have a child! (Informant \# 7, woman).

One of the women describing her first step in the recovery process said that she asked for permission to leave the hospital, took the bus to her home and baked a cake. She then returned to the hospital, but it had been a first small step of independence, which she recognised as the turning point in her illness. The woman described her recovery as a time of hard work, which sometimes made progress and sometimes had setbacks.

\section{And I just knew that this will work! And it was only that, this will work! But there was so much to it! RECOVERY is not an easy option! (Informant \# 8, woman)}

Another woman also took a decision to return to everyday life and not to let the illness and previous negative experiences in life take more space than what is necessary to make life work. Her decision to recover was a step in the direction of health.

\section{And I often say to my children that you really make your own decisions and you have to decide yourself how much of this is allowed to affect you. What do I do with this experience now - today? (Informant \# 9, woman)}

The bed of one woman became a refuge she regarded as her own turf which others had no access to. It became a haven where she experienced rest and tranquillity and this territory became her source of recovery.

\section{So then it was after all my little refuge, my bed upstairs, where I could go and be by myself. So in that way it was something that was for the better. (Informant \# 11, woman).}

Although one woman's condition did not improve until she clearly decided to take hold of the situation and choose to get better, in order to leave the hospital and return to her home and family, she experienced the medication she had to take due to her illness as a significant limitation in her life and feelings.

You cannot medicate your life and emotions away. Instead you need to take hold of your situation, but with help from other people, of course. (Informant \# 9, woman).

The relatives felt that the woman's recovery took time and required a lot of help and support after her discharge from the hospital. But slowly ordinary life came back. None 
of them talked about a turning point or a decision, but one partner put it this way.

\begin{abstract}
After about six weeks my wife started to get better and every week things seemed to get better and better. Slowly, my wife was becoming her old self once again. The medication was really working. My wife started feeling good about being with our daughter and things were looking up, and the whole experience began to fade like a dream. (Informant \# 6, partner).
\end{abstract}

\section{Own Recovery}

When the women knew they were on the mend, they described it as strength that was returning. During much of the illness they had been almost constantly bedridden, sometimes in foetal position, but when their strength began to return the women started to feel good about getting up in the mornings. Then they knew recovery was within reach. When anxiety no longer troubled them early in the morning, preventing them from starting the day, then they felt they would fight and ultimately win over the illness.

When I'm able to get out of bed in the mornings, then I know that I'm about to get better; when I no longer wake up between 22.30 with anxiety in the mornings. And when I wake up normally and can get out of bed. (Informant \# 10, woman).

When the illness began to recede, one of the women felt a need of peace and quiet, and that she needed to be alone and not to meet and talk to too many people. This woman isolated herself, which made her less paranoid. Solitude was easier on her and for her it led to improvement.

The fewer people I spoke with, the better it was. So for a few weeks I was there alone with my daughter. And there in my solitude I was actually better. It made me feel better to have fewer people to talk to, it made me less paranoid. (Informant \# 12, woman).

\section{Social Recovery}

The ability to socialise was a sign of recovery. From not wanting or coping with social contacts at all, the desire to socialise with others, above all with former friends, slowly began to return. But even new contacts were made, often with someone who had similar postpartum problems.

\begin{abstract}
And at the same time, it was these mothers that I started to meet with too. We did not talk much about what we had been through, but we did things together. We had coffee, we went on excursions, and we barbecued hot dogs outside and so. It was very nice to get out and do things together. (Informant \# 11, woman).
\end{abstract}

The experience of recovery consisted of different aspects. Someone described that a good feeling was when her baby was growing older and she could communicate with it more. Another had an experience of recovery when she could start to connect with other mothers, i.e., in different social contexts, such as "open preschool" and "church children's hours". One woman experienced a huge change when she and her child could go on a trip abroad by themselves, to a place where nobody knew her and she could leave the feeling that everyone knew about her illness.

I went to x-country in November with my little
daughter and she was nine months old at that
time, and I went alone with her. And people
were really confused about this. But when I
came home from this trip I felt 50 times better!
There I had not met anyone who knew
someone that knew someone who had talked to
someone about me and so. I was completely
unknown and it was good for my recovery.
(Informant \#12, woman).

One of the women experienced a colleague as her biggest support, and had the feeling that this colleague saved her from continuing in her illness. The colleague talked to the woman, supported her, called her on the phone and did not give up, even when the situation was difficult, which led to the woman eventually coming back to her work.

And what really saved me and helped me get
out of this and made me as a person again was
a colleague who deputised for me. We had not
known each other from before, and had never
previously met. But she was my support.
(Informant \# 13, woman).

The women subsequently discovered the joy of caring for their babies. From being psychotic with little interest in their child, the women rediscovered the joy of their newborns, as well as the pleasure of caring and being a mother again.

So there was much joy in taking care of my baby, but it was ... well, it was probably at around six months that it began to turn a little. We had more contact with others and so. (Informant \# 7, woman).

A part of one woman's recovery was her decision to take time for herself and not to build all of her life around her child. To cope she understood that she must have her own time in which she could meet friends and cultivate some of her own interests. Therefore, she reorganised the child's care, among other things, her partner looked after the baby at times so that the woman had time of her own.

I did not build my life so that it suited only my child, and everything would revolve around my child, but I wanted to do my own things. And I've finally realised that I cannot do everything at once, but gradually I will be able to, in a few years' time. (Informant \# 11, woman).

To "just be" was part of the recovery. A partner described how they travelled abroad and now and then had time for each other, which helped the recovery process move in the right direction. For the first time they could feel they were a united family that had time for each other and could recover together.

And we went on vacation for the first time, we went to $X$-country and our son was about 5-6 
months old. And it was the first time we felt good. We had time together, to just be. And it was very nice. He could sit with us when we were at a restaurant, and when he slept we could sit and talk. And it is almost the first time we felt we belonged together and that we were a family, where it worked. (Informant \# 6, partner).

\section{Supporting Circumstances}

To regain their health, the women needed support in different situations. Especially important was the support from partners and family, but the support from professionals was also essential. Members of this support network not only helped the women care for the child and the home, but also contributed to the recovery by discussing the causes and effects of the illness, why it had struck them, as well as exploring events in the women's background.

\section{Support of Relatives and Friends}

Relief and support was a prerequisite for the women's recovery, often from family members whose contribution was invaluable. This woman describes the tremendous support of her father that contributed to her own recovery and helped her partner so that he could cope with his work situation while having the sole responsibility for their child.

Our support was my dad, grandpa, he did that. He fed the baby and it was he who relieved the burden for both my husband and me. So we were with him quite a lot, a few days at a time sometimes. And he could help. (Informant \# 13, woman).

One partner described how the support from relatives and neighbours played an extremely important part, both in his wife's recovery and in his own life. Their support brought the family closer together, making it stronger, because they had to fight this condition together.

We have my sister and my brothers and my mother, who all live pretty close and we had people around us who could support and help. This means a lot to us, because if we had lived in another place it would have been different. We had to get some relief for ourselves too. We became even closer than before; you get other dimensions, not just this superficial cheerfulness. Instead, we were forced to struggle together, everyone. (Informant \# 1, partner).

The mother of one woman felt her daughter needed a lot of help from the relatives. The woman could not manage very much during her illness, and needed help all the time. Nevertheless, eventually the woman became stronger, but the help from relatives was needed for a long time.

So twice a week, I could help with my grandson. My daughter could not manage much. So I took care of him a lot, as much as I could. My son-in-law was amazing too. I could not wish for better. But help was needed for a long time. (Informant \# 5, grandparent).

\section{Professional Support}

Several of the women were counselled by professionals, such as a psychologist or therapist, which they perceived as good help in their recovery. During counselling, the women's childhood and adolescence were discussed. One woman found this extremely beneficial in helping her to understand the background to her inability to take care of her child, and to feel as a mother. The therapy helped to build her identity as a mother.

At least I wanted someone to talk to, which I
got when my son was about one year old. And
I concluded this contact now, barely three
weeks ago. So, it has taken 18 years to deal
with this backpack of mine...! (Informant \# 7 ,
woman).

Two of the women were supported by social services after returning home from the hospital. In the initial period, they were assisted on a daily basis by the home help service which took care of their homes and children. It helped their recovery.

And we had those "home helpers" at that time, when I was admitted first, but even when I was discharged and came home again. And we had two ladies, very self-assured women who came to our home ... / /. and even if they just made sure the kids were okay and were not injured, then I was satisfied. My older daughter thought it was really nice that these ladies were at home and that they baked and it smelt good..... (Informant \# 10, woman).

\section{Support Through Medication}

Medication contributed to the recovery of all the women. However, this woman experienced the medication as a disadvantage, but when her medication was changed one year postpartum, she felt that recovery had begun, that life had definitely started to return.

Once I got those new tablets when he was a year old, my condition started to slowly, slowly improve and I finally felt better. (Informant \# 11, woman).

Medication might be considered useful, but also a limitation in the women's lives. Like these two women felt very affected by their medication, and got better when it was decreased and stopped.

Yes, it was ok with the medication at the time, but I became very dull and lethargic of it. Slowly I got better when I came home again. But nobody told me if I should reduce the medication, so I just continued. The first year was not an easy year, no it wasn't. And to some extend I blame the medication for that. (Informant \# 7, woman). 
My real improvement started when I finally stopped all the heavy medication. I was like a zombie. And when I stopped my medication I came back and became my old self again. And I remember it so well, it was such a wonderful feeling! (Informant \# 13, woman).

The next of kin of one woman felt that she now had the help of a good psychiatrist who had wisely begun to reduce her medication. This was perceived as very positive support during her recovery.

Now she has a good psychiatrist, at an outpatient clinic, who has taken it all very carefully and has reduced the medication very slowly. (Informant \# 4, grandparent).

One partner experienced his wife had become very different from the medication, and not before it was decreased could he start to recognize her again. His experience was that the medication made her like a zombie.

\begin{abstract}
She changed a lot at first when she began to take the medication. It really changed her, she became like a zombie. Yes, emotionally, she became jaded by the medication. I couldn't recognize her. (Informant \# 1, partner).
\end{abstract}

\section{The Final and Overall Theme: Light in the Tunnel of Darkness}

Initially, the women experienced their illness as a period of darkness and despair, like shadows of darkness with only a small glimmer of light. The next phase consisted of a slight desire to return to life, to the usual. It was still dark, but far away in the darkness it began to brighten, a light was gradually becoming stronger in the dark tunnel. However, the key to recovery was an emerging internal decision to get well. From the perspective of the next of kin, the illness was equally dark and consisted of a lot of work and support for the families in need. Their loved ones did, however, slowly improve and the light became brighter even for the next of kin. They could start to relax in the understanding that recovery and health was within reach.

\section{DISCUSSION}

The aim of the present study was to explore the recovery process of postpartum psychosis from the perspective of the women, the women's partners and the next of kin, with regard to the experiences of the process at the conclusion of hospital care as well as following discharge.

The overall theme of their perspective is that the illness was a time filled with darkness and despair, but when the desire to live again returned to the women, the light also started to brighten. The women and their next of kin described the turning point, their own mental as well as social recovery, the support they received from relatives, friends, and professionals, and the support from medication.

The importance of having hope and faith in the ability to change the situation is said to be necessary for the recovery of a mental illness [1, 34-36]. Without hope, patients could be conquered by the mental disorder and remain passive. Smith [36] argues that hope becomes important when it is translated into a driving force and a desire to recover. To regain control and responsibility over their lives can increase patients' hope and sense of importance [37]. According to Schön [38], recovery is a social process in which the social relations are crucial for recovery.

Recovery usually occurs when people with mental disabilities discover or rediscover their strengths and the opportunities to pursue personal goals and a sense of self that allows them to grow, despite any residual symptoms and difficulties [39]. Several of the women had taken this turning point as the start of their description of how their journey of recovery began. They explained how they came to a point in their illness where they decided to get well, and this single emerging decision was the key to recovery. This changed the course of the illness, their strength and fighting spirit began to return, which accelerated the recovery process. There is no guide book describing how the recovery from serious mental illness occurs. It may, for example, be described as a process, or that it has one or more turning points usually explained as defining moments, sudden and unexpected changes which may be positive or negative. When we say that we have reached a turning point in our lives, we often associate it with life taking new and different directions. But to reduce the risk of the illness recurring, women should be offered the opportunity to process and understand why they became ill and should a woman decline such an opportunity, she should be encouraged to accept it [6]. Gaining such knowledge can also be important for preventive purposes.

One symptom of anxiety is waking up very early in the mornings. When the women were able to sleep through the night, it was a sign of recovery. Getting a good night's sleep is important for patients undergoing psychiatric treatment, and their sleep pattern at night must be considered an important aspect by the night nursing staff, in their care of these patients. According to Hunter et al. [40], strategies that can improve sleep effectiveness and reduce any disturbances that could disrupt sleep may lead to improved mental and physical well-being for the new mother. Sharma [41] reports that insomnia postpartum is one of the main reasons for the high risk of PPP relapse.

During the period of illness, the women felt no desire for companionship. They isolated themselves and managed nothing, not even their family. When the illness began to subside, the longing for friends and companionship increased. Being involved in meaningful activities and feeling needed are considered key ingredients in the recovery process. Pursuing educational, work, or spiritual activities can create a more meaningful life for the individual $[42,43]$.

Patients with serious mental disorders can easily lose their friends, but the women were supported by their relatives and friends throughout the illness. Several of the women could not cope with the daily chores and needed help. One of the most important aspects in the recovery process is the support from other people. Topor [44] discusses the importance of other people in the recovery process and describes how family and friends can represent indirect hope that the individual can identify with and reassess himself to, as well as relying on their support for solving practical problems. Recovery is reported as being a social process and to have someone by your side who believes in the recovery is crucial, according to reports [42, 45]. Having the support of a relative, friend, professional, or 
someone with personal experience of mental illness, does help in difficult times, someone who applauds the small successes and recalls that the individual is a complete person despite severe mental illness $[1,42,44,46]$. The women pointed out the need to meet others with similar problems, which is emphasised by Mead and Copeland [35] who argue the importance of having contact with other people who have experience of mental illness and recovery and who can function as a sort of mentor for the women in their recovery process, and as role models for recovery.

When professionals act in a supportive capacity, they are described as being donors of hope, available when needed, and flexible in what may support a recovery process [1]. Several researchers maintain that a supportive relationship from staff involves the use of their professional knowledge in collaboration with the patient, in a changing and complex process $[46,47]$. It should also be said that attentive care of a woman who develops PPP requires thorough assessments of high professionalism. Therefore, it is important to maintain a good working relationship between professionals using a holistic family perspective [3,7]. All forms of collaboration in which different professions join forces and together plan the recovery measures for a patient, can be seen as a very effective approach.

The importance of medication for the recovery was described differently by the women. Some felt they had not been helped by taking medication, while others even believed they had become worse, mainly due to the side effects. Others indicated that the medication had been one of several treatment measures that had helped or had been the single most important factor in the recovery. This is in accord with the findings of Schön et al. [48] after interviewing 58 patients who had recovered from mental illness. The authors point out that the main reasons for recovery were social contacts, such as family and friends, as well as professionals, while the remaining factors were medication, hospital admissions, therapeutic interventions, and activities initiated by social services and user organisations.

\section{Strengths and Limitations}

The first author's familiarity with women suffering from PPP, due to her psychiatric nursing work in Sweden, was the strength of this study. Given her clinical experience, it was easy for the researcher to promote a calm and supportive environment during these personal interviews. The small sample size (women, $n=7$ and relatives, $n=6$ ) may be the limitation of this study, but the richness of the interview material and the descriptions of relevant experiences provided a deep understanding of the phenomenon in question. Quotations from transcripts are provided. In addition, efforts to optimise the interview situation, by making the informants feel at ease during the interviews, also facilitate credibility.

The two authors with diverse backgrounds might affect the interview and interpretation of the data. The first author got used to the context of the study and this might imply preunderstandings that are difficult to disregard. To reduce this she tried at all times to be aware of this. The second author has no experience of psychiatry, but has long experience of qualitative analysis, and therefore provided objectivity in the analytical process. However, detailed descriptions of data collection and analysis have been provided, and different perspectives were put in the analysis by the author's different experiences. Despite the findings in this study might not be generalized, some of them could be transferred to similar settings and social groups with these specific recovery experiences [49]. Confirmability in this study is fulfilled by the fact that the interviews were recorded and then transcribed verbatim and analysed with a very high degree of accuracy.

In addition, snowball sampling might limit sample recruitment and thus induce its selection bias. The first few participants could have strong impact on the later samples due to their knowledge of and relationships with each other. In addition, those who accepted to participate might have already recovered, while those who were not feeling well would not participate. Hence, this might give a biased selection. According to Denscombe [50] snowball sampling is particularly useful for study of social groups where the participants tend to hide their identity for various reasons such as women with mental illhealth. The procedures could also be useful to study the "rare elements", that was small groups scattered over a wide area, but kept in touch with each other in other ways (for example, members of minority religions, specific groups and associations), and reduced the time for the sample selection or recruitment, especially when it was a small-scale research [50]. A limitation is the time that passed since the women's time of illness. But the illness is a time the women will never forget and which leaves traces for life. One of the women mentioned that to be able to talk about the time of illness, long time must have passed, because the memories are so difficult. One woman had written her story down so she would not forget and waited for someone to come in and use her story in some context.

\section{CONCLUSION}

To summarise this study, recovery from a mental illness requires hard work and the key to the women's recovery was the decision to get well made by them. The disorder causes darkness, but when the recovery began, a light in the dark tunnel started to shine and gradually grew stronger. The nursing staff must be aware that a good night's sleep is important for patients undergoing psychiatric treatment, and that recovery will occur step by step. The nurse needs to give hope, encouragement, and help the patient recognise the strengths that exist within. In order to reduce the risk of a relapse, the nursing staff needs to offer follow up visits after recovery. Family and friends need to be taken in account for the women's recovery, and for some of them social services and user organizations might be of use.

\section{CONFLICT OF INTEREST}

The manuscript has been submitted exclusively to The Open Nursing Journal and there is no conflict of interest.

\section{ACKNOWLEDGEMENTS}

The study was supported by the Department of Psychiatry at Skaraborg Hospital and the King Oscar II and Queen Sophia Golden Wedding Anniversary Foundation.

\section{REFERENCES}

[1] Engqvist I, Nilsson A, Nilsson K, Sjöstrom B. Strategies in caring for women with postpartum psychosis--an interview study with psychiatric nurses. J Clin Nurs 2007; 16(7): 1333-42. 
[2] Engqvist I, Ferszt G, Åhlin A, Nilsson K. Psychiatric nurses' descriptions of women with postpartum psychosis and nurses' responses - An exploratory study in Sweden. Issues Ment Health Nurs 2009; 30(1): 23-30.

[3] Engqvist I, Åhlin A, Ferszt G, Nilsson K. Nurses - psychiatrists' main collaborators when treating women with postpartum psychosis. J Psychiatr Ment Health Nurs 2010; 17(6): 494-502.

[4] Engqvist I, Ferszt G, Åhlin A, Nilsson K. Women's experience of postpartum psychotic episodes - analyses of narratives from the Internet. Arch Psychiatr Nurs 2011; 25(5): 376-87.

[5] Engqvist I, Åhlin A, Ferszt G, Nilsson K. Comprehensive treatment of women with postpartum psychosis across health care systems from Swedish psychiatrists' perspective. Qual Rep 2011; 16(1): 66-83.

[6] Engqvist I. Experiences of postpartum psychosis from the perspective of women with the diagnosis and psychiatric nurses. $\mathrm{PhD}$ [dissertation]. University of Rhode Island, USA 2011. http://pqdtopen.proquest.com/\#abstract?dispub=3450794

[7] Engqvist I, Nilsson K. Involving the family in the care and treat-ment of women with postpartum psychosis: Swedish psychiatrists' experiences. Psychiatry J, Retrieved 2013, January 11 from web-site: http://www.hindawi.com/journals/psychiatry/2013/897084/abs/

[8] Engqvist I, Nilsson K. Experiences of the first days of postpartum psychosis - an interview study with women and next of kin in Sweden. Issues Ment Health Nurs 2013; 34(2): 82-9.

[9] Kendell R, Chalmers J, Platz C. Epidemiology of puerperal psychoses. Br J Psychiatry 1987; 150(5): 662-73.

[10] American Psychiatric Association: Diagnostic and statistical manual of mental disorders (3rd ed.). Washington, DC: Author; 1980.

[11] Brockington I. Postpartum psychiatric disorders. The Lancet 2004; 363(9405): 303-10

[12] Phulmann B, Stöber G, Franzek E, Beckmann H. Cycloid psychoses predominate in severe postpartum psychiatric disorders. J Affect Disord 1998; 50(2-3): 125-34.

[13] Friedman S, Resnick P, Rosenthal M. Postpartum psychosis: Strategies to protect infant and mother from harm. J Fam Pract 2009; 8(2): 40-6.

[14] Heron J, Gilbert N, Dolman C, et al. Information and support needs during recovery from postpartum psychosis. Arch Womens Ment Health 2012; 15(3): 155-65.

[15] Cantwell R, Cox JL. Psychiatric disorders in pregnancy and the puerperium. Curr Obstet Gynaecol 2006; 16(1): 14-20.

[16] Friedman S, Horwitz S, Resnick P. Child murder by mothers: A critical analysis of the current state of knowledge and a research agenda. Am J Psychiatry 2005; 162(9): 1578-87.

[17] Blackmore ER, Rubinow DR, O'Connor TG, Tang LX, Craddock N, Jones I. Reproductive outcomes and risk of subsequent illness in women diagnosed with postpartum psychosis. Bipol Disord 2013; 15(4): 394-404.

[18] Sit D, Rothschild AJ, Wisner KL. A review of postpartum psychosis. J Womens Health 2006; 15(4): 352-68.

[19] Nager A, Sundqvist K, Ramírez-León V, Johansson LM. Obstetric complications and postpartum psychosis: a follow-up study of 1.1 million first-time mothers between 1975 and 2003 in Sweden. Acta Psychiatr Scand 2008; 117(1): 12-9.

[20] Phulmann B, Stöber G, Beckmann H. Postpartum psychoses: Prognosis, risk factors, and treatment. Curr Psychiatry Rep 2002; 4(3): $185-90$.

[21] Bågedahl-Stridlund M, Ruppert S. Parapartum mental illness: A longterm follow-up study. Psychopathology 1998; 31(5): 250-9.

[22] Bågedahl-Stridlund M. Parapartum mentally ill mothers and their children. $\mathrm{PhD}$ [dissertation] Karolinska Institute, Institute for Psychiatry: Stockholm, Sweden 1987.

[23] Engqvist I, Nilsson K. Men's experiences of their partners' postpartum psychiatric disorders - narratives from the Internet. Ment Health Fam Med 2011; 8(3): 137-46.

[24] Matthey S, Barnett B, Ungerer J, Waters B. Paternal and maternal depressed mood during the transition to parenthood. J Affect Disord 2000; 60(2): 75-85.
[25] White M, Wilson M, Elander G, Persson B. The Swedish family: Transition to parenthood. Scand J Caring Sci 1999; 13(3): 171-6.

[26] Anthony W, Farkas M. The essential guide to psychiatric rehabilitation practice. Boston, MA: Boston University 2012.

[27] Skärsäter I. Mental health nursing. (In Swedish). Studentlitteratur Sweden 2010.

[28] Syrén S. The unspoken and disobedient suffering. Existence for people with chronic psychotic illness and their families. $\mathrm{PhD}$ [dissertation]. Linnaeus University: Sweden 2010.

[29] Antonovsky A. The structure and properties of the sense of coherence scale. Soc Sci Med 1987; 36(6): 725-33

[30] Kvale S, Brinkmann S. The qualitative research interview. $2^{\text {nd }}$ ed. (in Swedish). Studentlitteratur: Lund, Sweden 2009.

[31] Mischler EG. Research interviewing. Context and Narrative. Cambridge, MA: Harvard University Press, USA 1986.

[32] Polit D, Beck CT. Nursing Research: Generating and Assessing evidence for nursing practice, $9^{\text {th }}$ ed., Lippincott Williams \& Wilkins 2012.

[33] Graneheim U, Lundman B. Qualitative content analysis in nursing research: concepts procedures and measures to achieve trustworthiness. Nurs Educ Today 2004; 24(2): 105-12.

[34] Deegan P. Recovery as a journey of the heart. Psychiatr Rehabil J 1996; 19(3): 91-7.

[35] Mead S, Copeland M. What recovery means to us: Consumers' perspectives. Commun Ment Health J 2000; 36(3): 315-28.

[36] Smith M. Recovery from severe psychiatric disability: Findings of a qualitative study. Psychiatr Rehabil J 2000; 24(2): 149-59.

[37] Davidson L, Borg M, Marin I, Topor A, Mezzina R, Sells D. Processes of recovery in serious mental illness. Findings from a multinational study. Am J Psychiatr Rehabil 2005; 8(3): 177-201.

[38] Schön UK. Women's and men's recovery from mental disorders (In Swedish). PhD [dissertation]. Stockholm University Sweden 2009.

[39] Meuser KT, Corrigan PW, Hilton DW, Tanzman B, Schaub A, Gingerish S. Illness management and recovery: A review of the research. Psychiatr Serv 2002; 53(10): 1272-84.

[40] Hunter L, Rychnovsky J, Yount S. A selective review of maternal sleep characteristics in the postpartum period. J Obstet Gynceol Neonatal Nurs 2009; 38(1): 60-8.

[41] Sharma V. Role of sleep loss in the causation of puerperal psychosis. Med Hypotheses 2003; 61(4): 477-81.

[42] Davidson L. Living Outside Mental Illness: Qualitative Studies of Recovery in Schizophrenia, New York University Press: USA 2003.

[43] Sullivan WP. A long and winding road: The process of recovery from mental illness. Innov Res 1994; 3(3): 14-24.

[44] Topor A. Managing the contradictions. Recovery from severe mental disorders. $\mathrm{PhD}$ [dissertation]. Stockholm University: Sweden 2001.

[45] Topor A, Borg M, Mezzina R, Sells D, Marin I, Davidson L. Others: the role of family, friends and professionals in the recovery process. Am J Psychiatr Rehabil 2006; 9(1): 17-37.

[46] Borg M. The nature of recovery as lived in everyday life: Perspectives of individuals recovering from severe mental health problems. $\mathrm{PhD}$ [dissertation]. Norwegian University of Science and Technology Dep. of Social Work and Health Science: Norway 2007.

[47] Green CA, Polen MR, Janoff SL, et al. Understanding how clinicianpatient relationships and relational continuity of care affect recovery from serious mental illness: STARS study results. Psychiatr Rehabil J 2008; 32(1): 9-22.

[48] Schön UK, Denhov A, Topor A. Social relationships as a decisive factor in recovering from severe mental illness. Int J Soc Psychiatry 2009; 55(4): 336-47.

[49] Lincoln YS, Guba EG. Naturalistic inquiry. SAGE Publications: Newbury Park: London 1985.

[50] Denscombe M. The Good Research Guide for small-scale social research. $3^{\text {rd }}$ ed. London: Open University Press 2007. 